\title{
On the Generality of the Latitudinal Diversity Gradient
}

\author{
Helmut Hillebrand ${ }^{\star}$
}

Erken Laboratory, Department of Limnology, Evolutionary Biology Centre, University of Uppsala, Norr Malma 4200, S-76173 Norrtälje, Sweden; and Leibniz-Institut für Meereswissenschaften, University of Kiel, Marine Ecology, Düsternbrooker Weg 20, D24105 Kiel, Germany

Submitted May 19, 2003; Accepted August 8, 2003; Electronically published January 15, 2004

Online enhancements: appendixes.

ABStRACt: The decline of biodiversity with latitude has received great attention, but both the concise pattern and the causes of the gradient are under strong debate. Most studies of the latitudinal gradient comprise only one or few organism types and are often restricted to certain region or habitat types. To test for significant variation in the gradient between organisms, habitats, or regions, a meta-analysis was conducted on nearly 600 latitudinal gradients assembled from the literature. Each gradient was characterized by two effect sizes, strength (correlation coefficient) and slope, and additionally by 14 variables describing organisms, habitats, and regions. The analysis corroborated the high generality of the latitudinal diversity decline. Gradients on regional scales were significantly stronger and steeper than on local scales, and slopes also varied with sampling grain. Both strength and slope increased with organism body mass, and strength increased with trophic level. The body masseffect size relation varied for ecto- versus homeotherm organisms and for different dispersal types, suggesting allometric effects on energy use and dispersal ability as possible mechanisms for the body mass effect. Latitudinal gradients were weaker and less steep in freshwater than in marine or terrestrial environments and differed significantly between continents and habitat types. The gradient parameters were not affected by hemisphere or the latitudinal range covered. This analysis is the first to describe these general and significant patterns, which have important consequences for models aiming to explain the latitudinal gradient.

Keywords: macroecology, species richness, trophic level, body mass, habitat.

\footnotetext{
* Present address: Leibniz-Institut für Meereswissenschaften, University of Kiel, Marine Ecology, Düsternbrooker Weg 20, D-24105 Kiel, Germany; email: hhillebrand@ifm.uni-kiel.de.

Am. Nat. 2004. Vol. 163, pp. 192-211. (c) 2004 by The University of Chicago. 0003-0147/2004/16302-30195\$15.00. All rights reserved.
}

Differences in the number of coexisting species already fascinated early naturalists (Darwin 1859; von Humboldt [1828] 1993) and remain a central aspect of ecological research (Gaston and Blackburn 2000). No single pattern of biodiversity has fascinated ecologists more than the increase of richness toward the Tropics (Pianka 1966; Rohde 1992; Rosenzweig 1995; Gaston and Blackburn 2000). Still, there is an astonishing lack of consensus about the mechanisms leading to this spatial variation in diversity. An obstacle to the search for a primary cause for this latitudinal gradient has been the ever increasing number of hypotheses (Pianka 1966; Rohde 1992), their interdependence (Currie 1991; Gaston and Blackburn 2000), and the lack of rigorous falsification (Currie et al. 1999).

The debate on causes for the latitudinal gradient of diversity features biological and nonbiological explanations. Mid-domain models use random placement of species ranges in a domain (Earth) with hard boundaries (the poles) to predict a peak in diversity in the middle of this domain (equator) without invoking any ecological or evolutionary processes (Colwell and Hurtt 1994; Colwell and Lees 2000). Subsequent tests of the mid-domain model revealed high predictive power of such models for global (Lyons and Willig 1997; Jetz and Rahbek 2001; Koleff and Gaston 2001) and regional data sets (Lees et al. 1999), whereas others found strong differences between predicted and observed diversity patterns (Bokma et al. 2001; Diniz et al. 2002). For mid-domain models, latitude represents the geometric constraint imposed on the range size of species. All other models use latitude as a surrogate variable for one or several factors co-varying with latitude. Gradients of decreasing energy (and water) supply (Currie 1991; Allen et al. 2002) and decreasing biome area (Rosenzweig 1995) toward the poles have been proposed as ultimate causes for the latitudinal diversity decline. There is continuing debate about the relative importance of these different covariates and their possible interactions (Currie 1991; Rohde 1997; Rosenzweig and Sandlin 1997). Changes in the intensity or specificity of ecological interactions (competition, predation, parasitism) with latitude were also proposed as ultimate causes (Pianka 1966), but several recent contributions failed to observe consistent changes in interactions across latitude (Lambers et al. 2002; 
Ollerton and Cranmer 2002). The effective evolutionary time hypothesis (Rohde 1992) finally assumes higher speciation in the Tropics as the major process increasing diversity at low latitudes. The higher diversification is based on higher energy increasing mutation rates and decreasing generation times (Cardillo 1999), larger area increasing speciation (Losos and Schluter 2000), and higher temporal stability on geological time scales enhancing clade persistence (Jansson and Dynesius 2002).

Support for these major hypotheses is mainly based on simple correlations between diversity and richness employing a highly biased selection of organisms (Rohde 1992; Hillebrand and Azovsky 2001). Often, only one group of organisms (or a limited number of related groups) has been used to test the major hypotheses for the latitudinal diversity gradient. Moreover, the main focus has been on vertebrate taxa and higher plants, and a majority of studies originated from the Americas. The predominance of single-gradient studies counteracted the notion of generality within the latitudinal diversity debate. There is rather weak knowledge of how ecological and evolutionary features of the organisms, geographic positions, and habitat characteristics change the structure of the latitudinal gradient.

Meta-analysis (Gurevitch and Hedges 1993; Rosenberg et al. 2000) represents a suitable technique to analyze latitudinal gradients across different biota and regions and thus to generalize findings on the latitudinal distribution of species richness. I assembled nearly 600 gradients from the literature, and each gradient was characterized by the standardized correlation coefficient $\left(r_{z}\right)$ and the slope $(b)$ of the relation between diversity and latitude. This database was used to test the following hypotheses.

Hypothesis 1. The latitudinal gradient is a general pattern across all organisms and habitat types. Generality is defined here as the overall significance of the strength $\left(r_{z}\right)$ and the slope $(b)$ across the complete database as opposed to invariability, which is defined as consistency of the magnitudes $r_{z}$ and $b$ across organisms and habitats.

Hypothesis 2. The magnitude of $r_{z}$ and $b$ varies significantly with characteristics of the measurement such as (a) the spatial scale of diversity assessment, (b) the range of latitudes covered, and (c) the diversity measure.

Hypothesis 3. The magnitude of $r_{z}$ and $b$ varies significantly with organism characteristics such as (a) body mass, (b) dispersal type, (c) trophic level, and (d) thermoregulation.

Hypothesis 4. The magnitude of $r_{z}$ and $b$ varies significantly between geographic regions such as (a) different continents or oceans and (b) the hemispheres.

Hypothesis 5. The magnitude of $r_{z}$ and $b$ varies significantly (a) between terrestrial, freshwater, and marine realms and (b) between habitat types.

\section{Methods}

Data

Four abstracting services were searched: Cambridge Biological Abstracts (1988-2002), ISI Web of Science (19862002), JSTOR (until 1998), and the Aquatic Science and Fisheries Abstracts (1978-2002). The search strings were "latitudinal gradient," "latitude AND diversity," and "latitude AND species richness." More recent papers were included if present and also papers derived from the bibliographies of the papers screened. To broaden the basis of this analysis and to reduce the impact of publication bias, I also included studies that were not originally designed to test for latitudinal gradients but that reported diversity measures across different latitudes. The search revealed more than 1,000 studies, which were checked for the following criteria: measurement of diversity of a defined target organism group at a minimum of three locations spanning a minimum latitude range of $10^{\circ}$. Two hundred thirty-two studies passed these criteria, reporting a total of 581 gradients (see app. A in the online edition of the American Naturalist). To calculate effect sizes, I obtained the correlation coefficient $r$, the slope $b$, its standard error $\left(\mathrm{SE}_{b}\right)$, the intercept $a$, and the number of observations $(N)$ from each gradient.

\section{Effect Sizes}

Effect size is the general term for the parameter used to measure the effect of a treatment or a variable within each study, that is, in the present case the effect of latitude on diversity. The choice of relevant effect sizes is a critical step in meta-analysis (Osenberg et al. 1999). Meta-analyses allow one to obtain quantitative central tendencies in effect sizes over a large number of studies as well as the analysis of differences in the effect size between studies categorized with respect to grouping variables (Gurevitch and Hedges 1993; Rosenberg et al. 2000). The usefulness of metaanalysis is increased by accounting for the variance within studies, which is preferably done by a weighted analysis, where each effect size is weighted by the inverse of its sampling variance (Gurevitch and Hedges 1993).

Here, I described the latitudinal gradient of diversity by two effect sizes reflecting different aspects of the relation, the strength and the steepness. Throughout the article, I use strength to indicate the degree of variation of diversity around latitude, reflected by the correlation coefficient. Steepness is used to indicate how rapidly diversity declines with latitude, reflected by the slope. The gradient strength was defined as Fisher's $z$-transform of the correlation coefficient $r, r_{z}$, which is an established effect size in metaanalyses (Rosenberg et al. 2000) and can be weighted by a sampling variance $\operatorname{Var}_{r_{2}}$ : 
Table 1: Variables characterizing each gradient with respect to organism type, habitat, geographic position, and measurement details

\begin{tabular}{|c|c|c|c|}
\hline Variable name & $L$ & Groups $(k)$ & $k$ \\
\hline Thermoregulation & 2 & Ectotherm (440), homeotherm (139) & 579 \\
\hline Body mass (log g) & $\mathrm{CON}$ & Range: -9.41 to 4.71 ; mean: -.47 ; median: -.15 & 581 \\
\hline Dispersal type & 6 & Flying (170), mobility (136), pelagic larvae (119), seeds (73), passive (68), transfer (8) & 574 \\
\hline Trophic level & 7 & $\begin{array}{l}\text { Omnivores (280), autotrophs (87), herbivores (65), carnivores (58), suspension (34), } \\
\text { microbivores }(41) \text {, parasite (16) }\end{array}$ & 581 \\
\hline Realm & 3 & Terrestrial (305), marine (204), freshwater (69) & 578 \\
\hline Habitat & 16 & $\begin{array}{l}\text { All terrestrial (234), benthos coastal (102), pelagic ocean (39), lake (36), deep sea } \\
\text { (34), forest (31), all freshwater (23), coastal pelagic (20), nonforest (18), biota } \\
\text { (10), stream (10), soil (6), human (5), islands (5), estuary (3), cave (2) }\end{array}$ & 578 \\
\hline Hemisphere & 3 & $\mathrm{~N}(335), \mathrm{S}(180)$, both $(64)$ & 579 \\
\hline Longitude & 7 & $\begin{array}{l}\text { New World (183), Atlantic (112), Eurafrica (74), Australasia (43), Pacific (22), Indian } \\
\text { Ocean (19), worldwide (128) }\end{array}$ & 581 \\
\hline Scale & 2 & Regional (349), local (222) & 571 \\
\hline Grain $\left(\log \mathrm{km}^{2}\right)$ & $\mathrm{CON}$ & Range: 7 to -9.5 ; mean: 3.1 ; median 4.3 & 370 \\
\hline Diversity type & 3 & $\alpha(223)$, ranges $(182), \gamma(150)$ & 555 \\
\hline Range & $\mathrm{CON}$ & Range: 10-90; mean: 44.0; median: 44 & 571 \\
\hline Significance & 2 & Yes $(342)$, no $(206)$ & 548 \\
\hline Global richness $(\log )$ & $\mathrm{CON}$ & Range: $1.6-6$; mean: 3.8 ; median: 3.9 & 575 \\
\hline Measure & 5 & $S(415), S_{\text {st }}(70)$, mean $S(28)$, index (25), higher (33) & 581 \\
\hline
\end{tabular}

Note: Variable names and the number of group levels $(L)$ are given for each variable, name of group levels, and the numbers of gradients $(k)$ therein. The last column gives the total number of gradients for which information was obtained. Some categories requiring explanations are discussed in appendix B of the online edition of the American Naturalist. CON = continuous variable, for which range, mean, and median are given.

$$
\begin{gathered}
r_{z}=\frac{1}{2} \times \ln \left(\frac{1+r}{1-r}\right) \\
\operatorname{Var}_{r_{z}}=\frac{1}{N-3}
\end{gathered}
$$

The slope $b$ of the linear regression of diversity on latitude was used for gradient steepness with $\mathrm{SE}_{\mathrm{b}}$ as variance estimate (Hillebrand et al. 2001). The two effect sizes, $r_{z}$ and $b$, are not completely independent mathematically (A. P. Allen, personal communication), but they correlated rather weakly ( $r=0.17, N=540$ ). The use of effect sizes from linear regressions is arguably a simplification, but more complex regression models would decrease the comparability of the parameters and render the analysis impossible.

\section{Grouping Variables}

Each gradient was classified with respect to 14 variables characterizing the organism group, the habitat type, the geography, the scale, and the analytical details of each study. The definition of the categories aimed at a high level of standardization and reproducibility combined with a high level of retained information. The concise allocation of categories to each gradient is revealed in the enhancement material in the online edition of the American Nat- uralist (app. A). Table 1 summarizes the 14 variables and their group levels, whereas the concise definition for each level is given in appendix B of the online edition of the American Naturalist.

Organism types were characterized by their mode of thermoregulation, their body mass, their dispersal type, and their trophic level. Body mass estimates were obtained from the original contributions or from the literature (Peters 1983; Wetzel and Likens 1991). The habitats were characterized by realm and habitat type. Two categorical variables characterized the geographic position of the gradient, hemisphere and longitude (table 1).

Spatially, I characterized the scale as either regional or local (see below) and noted the sampling grain (mean sampled area) as continuous variable $\left(\log \mathrm{km}^{2}\right)$. The scale was local if diversity was assessed for certain sampling locations (defined sampling site) or certain habitats (single forests, single lakes), classically denoted $\alpha$-diversity (Loreau 2000). The scale was regional if diversity was measured for latitudinal grid squares (from $1^{\circ} \times 1^{\circ}$ up to $\left.5^{\circ} \times 5^{\circ}\right)$ or for larger regions covering many habitats (countries, biomes). Whereas the latter represents classical $\gamma$-diversity, the superposition of range maps on a grid system introduces an additional moment of spatial autocorrelation. Therefore, a third spatial variable (diversity type) was introduced to differentiate between $\alpha$-diversity, $\gamma$-diversity, and range-based diversity (table 1 ). Local and regional scales were characterized by widely differing sam- 
pling grains (log-transformed area; mean \pm SD: local, $-1.61 \pm 3.18$; regional, $4.73 \pm 1.25$ ).

Methodological differences between studies were analyzed in four different variables: the latitudinal range of the study, the significance of the original correlation of diversity to latitude, the global species richness of the defined group, and the measure of diversity used (table 1; see app. B for definitions). Global biodiversity of the organism group investigated was given in original studies or obtained from recent biodiversity assessments (mainly from Levin 2001).

The intention to show general patterns of the latitudinal gradient would be counteracted if a single level within one variable would dominate the analysis. This was generally not the case: although the number of studies per level varied tremendously, no categorical variable was entirely dominated by a single level (table 1). Defining dominance as the ratio of the number of studies in the most numerous level to the following level, the highest dominance is found for the variables diversity measure and trophic level. For the latter, many groups were treated as omnivores because they contain species that are herbivores, carnivores, or just omnivores. To test whether the observed pattern with trophic level was an artifact of the large number of omnivore studies, I analyzed suspension feeders as a separate group and found that they fit well between herbivores and omnivores (see "Results").

\section{Meta-analysis}

Weighted meta-analysis on $r_{z}$ and $b$ was used (Gurevitch and Hedges 1993; Rosenberg et al. 2000; Hillebrand et al. 2001) to calculate the overall magnitude of the parameters, called grand mean effect sizes, and their $95 \%$ confidence intervals (CIs) using the bootstrapping procedure in MetaWin 2.0 (Rosenberg et al. 2000). For all categorical variables (table 1), weighted meta-analyses were used to calculate groupwise effect sizes and their CIs. A random effect model was used (Gurevitch and Hedges 1993; Rosenberg et al. 2000; Hillebrand et al. 2001) to test whether the grouping variable explained significant heterogeneity in the effect sizes, whereby the overall heterogeneity in the effect sizes was divided into heterogeneity explained by the variable $Q_{b}$ and into residual heterogeneity $Q_{w}$. Significance levels for the analysis of heterogeneity were obtained by 9,999 randomizations. Significant difference between levels within variables was indicated by nonoverlapping CIs. For the continuous variables (table 1), a weighted regression analysis was conducted in MetaWin 2.0 (Rosenberg et al. 2000).

No factorial meta-analysis technique is available to date to account for interactions between the different variables. These interactions are obviously present between several variables, such as between scale and body mass, between body mass and many other organism characteristics, but also between trophic level, thermoregulation, and dispersal (e.g., autotrophs are all ectotherm and often have seed dispersal). I reduced the problem by separating the regional and local scales (see "Results") and by reanalyzing the regression of gradient parameters on body mass for different organism groups. Moreover, standard statistics allowing factorial combinations cannot replace metaanalysis because they do not account for the variability of the effect size describing each gradient (Gurevitch and Hedges 1993).

Multiple use of data required adjustment of significance levels, which was done using a Dunn-Sidak adjustment of $P$, with $P_{\text {adj }}=1-(1-P)^{1 / x}$, where $x=$ number of tests $=15$ and $P=$ significance level $(.05$ or .01$)$. Significance level adjustments are known to be highly conservative (Sokal and Rohlf 1995); therefore I will discuss not only significant differences but also trends with $P_{\text {adj }}<.1$.

\section{Results}

\section{Overall Effect Sizes}

The grand mean effect size for $r_{z}$ was negative $(-0.729)$ and significantly different from 0 (fig. $1 A$ ). The total heterogeneity indicated significant structure in the effect sizes $\left(Q_{\text {tot }}=756.95, P<.001\right)$.

The overall significance of the correlation between latitude and diversity was observed, although more than onethird of the original studies did not show significant relationships (table 1). Most interestingly, even the nonsignificant studies showed a general negative tendency, which differed significantly from 0 (fig. $1 B$ ). However, there was a strong difference in strength between significant and nonsignificant studies $\left(Q_{\mathrm{b}}=278.7, Q_{\mathrm{w}}=\right.$ 631.4, $\left.\mathrm{df}=1,522, P_{\mathrm{adj}}<.01\right)$.

For $r_{z}$, the actual measure of diversity did not significantly affect the effect size $\left(P_{\text {adj }}>.05\right)$. For $b$, however, the diversity measure significantly influenced the effect size $\left(P_{\text {adj }}<.01\right)$. Species richness $(S)$ resulted in steeper slopes than any other diversity measure. Therefore, I restricted the analyses involving $b$ to studies measuring species richness.

As for strength, the grand mean effect size for gradient slopes was negative $(-1.039)$ and differed significantly from 0 (fig. $1 A$ ). The total heterogeneity indicated significant structure in the effect sizes $\left(Q_{\text {tot }}=3,720.77, P<\right.$ $.001)$. The slopes showed the same difference between effect sizes reported from originally significant studies versus nonsignificant studies $\left(Q_{\mathrm{b}}=238.8, Q_{\mathrm{w}}=2,906.7, \mathrm{df}=\right.$ 

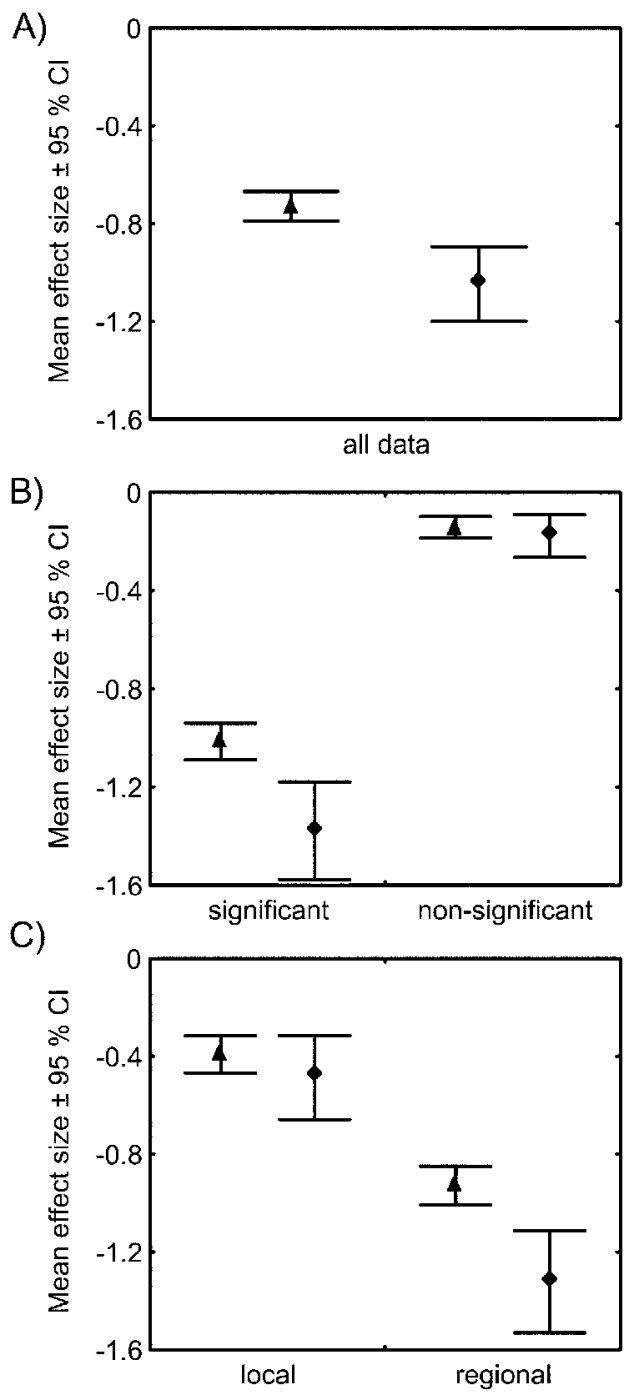

Figure 1: Mean effect size ( $\pm 95 \%$ confidence intervals) for strength $r_{z}$ (triangles) and slope $b$ (diamonds) of the latitudinal gradient of diversity. $A$, Overall effect size. $B$, Effect sizes for studies originally reporting significant or nonsignificant gradients. $C$, Effect sizes for gradients on local or regional scales.

1,365, $\left.P_{\text {adj }}<.01\right)$. Again, even nonsignificant studies showed a significant negative effect size for $b$ (fig. $1 B$ ).

The differentiation between regional and local studies had very strong impact on the effect sizes, both for $r_{z}$ and $b$ (fig. 1C). Regional gradients were significantly stronger $\left(r_{z} ; Q_{\mathrm{b}}=114.4, Q_{\mathrm{w}}=780.3\right.$, df $\left.=1,545, P_{\mathrm{adj}}<.01\right)$ and steeper $\left(b ; Q_{\mathrm{b}}=151.5, Q_{\mathrm{w}}=3,529.9, \mathrm{df}=1,370, P_{\mathrm{adj}}<\right.$ $.01)$ than local gradients. Still, the local gradients were significantly negative for both effect sizes (fig. $1 C$ ). The strong difference between regional and local gradients and the interference of other variables with scale suggested that the regional and local gradients be analyzed separately, which was done for all forthcoming analyses. Moreover, only regional data are presented graphically, while regional and local effect sizes can be found electronically (see app. $\mathrm{C}$ in the online edition of the American Naturalist).

\section{The Strength of the Latitudinal Gradient}

Body mass had consistent and strong effects on $r_{Z}$ at both spatial scales (table 2; fig. 2A). Please note that the contrast between highly significant regressions (table 2) and observed variance in the data (fig. $2 A$ ) comes from the use of weighted regressions. At both spatial scales, $r_{z}$ became more negative; that is, the gradient became stronger with increasing body mass of the organisms. Additionally, the slopes of the weighted regression were highly similar for regional and local gradients (table 3 ).

The strength of the latitudinal gradient did not generally differ with thermoregulation (table 2). Ectotherm and homeotherm organisms had remarkably similar effect sizes at regional (fig. 3A) and local scales, respectively. Because body mass and thermoregulation may be negatively correlated (ectotherms tending to be smaller), I analyzed whether the mode of thermoregulation changed the regression between body mass and effect size (table 3 ). Obviously, the stronger and steeper gradients at higher body mass were related to ectotherm organisms alone, whereas the homeotherms, covering a smaller range of body masses, did not reveal a negative relationship between effect size and body mass. At regional scales, the homeotherms showed even a strong positive relation between body mass and $r_{z}$ (table 3 ).

The dispersal types were not significantly different from each other at either scale (table 2; fig. $3 B$ ). However, the relation between body mass and $r_{z}$ was interlinked with dispersal type (table 3 ). Organisms with passively distributed dispersal stages (seeds, pelagic larvae) or passively transported adults tended to have steeper relationships between weight and $r_{z}$ than organisms able to move on their own force (flying, mobility).

At regional scales, a very strong impact of trophic level on $r_{z}$ was found (table 2; fig. 3C). Gradient strength consistently increased with higher trophic level. Significant differences were observed between autotrophs and herbivores on the one hand and omnivores and carnivores on the other. At the local scale, the impact of trophic level was less pronounced and nonsignificant but still with most negative gradients confined to carnivores (app. C). Two more trophic groups were present: the microbivores had gradient strengths similar to those of herbivores, whereas parasites differed strongly between regional and local scales (app. C).

The longitudinal position of the gradient affected $r_{z}$ sig- 
Table 2: Analysis of heterogeneity for the strength $\left(r_{z}\right)$ of the latitudinal gradient of diversity at either regional or local scales

\begin{tabular}{|c|c|c|c|c|c|c|c|c|c|c|c|c|}
\hline \multirow[b]{2}{*}{ Variable } & \multicolumn{6}{|c|}{ Regional } & \multicolumn{6}{|c|}{ Local } \\
\hline & $\mathrm{df}_{\mathrm{b}}$ & $Q_{\mathrm{b}}$ & $\mathrm{df}_{\mathrm{w}}$ & $Q_{w}$ & $P_{\text {rand }}$ & $P_{\text {adj }}$ & $\mathrm{df}_{\mathrm{b}}$ & $Q_{\mathrm{b}}$ & $\mathrm{df}_{\mathrm{w}}$ & $Q_{w}$ & $P_{\text {rand }}$ & $P_{\text {adj }}$ \\
\hline Body mass & 1 & 8.2 & 334 & 537.3 & .0011 & $\star *$ & 1 & 14.2 & 209 & 227.1 & .0001 & ** \\
\hline Thermoregulation & 1 & .03 & 332 & 542.5 & .8848 & NS & 1 & .1 & 209 & 234.5 & .7436 & NS \\
\hline Dispersal type & 5 & 19.2 & 328 & 539.6 & .0337 & NS & 5 & 9.7 & 201 & 227.7 & .1097 & NS \\
\hline Trophic level & 6 & 60.7 & 329 & 508.7 & .0001 & $* *$ & 6 & 14.9 & 204 & 224.6 & .0337 & NS \\
\hline Longitude & 6 & 193.2 & 329 & 550.7 & .0001 & $* *$ & 6 & 11.8 & 204 & 235.7 & .0835 & NS \\
\hline Hemisphere & 2 & 8.1 & 332 & 536.5 & .0782 & NS & 2 & 2.4 & 207 & 224.1 & .3187 & NS \\
\hline Realm & 2 & 34.3 & 331 & 531.0 & .0001 & $* *$ & 2 & 9.8 & 207 & 223.0 & .0108 & NS \\
\hline Habitat & 10 & 80.1 & 323 & 493.5 & .0001 & $* *$ & 14 & 58.3 & 194 & 231.6 & .0002 & $* *$ \\
\hline Grain & 1 & 2.5 & 264 & 464.2 & .6858 & NS & 1 & .1 & 89 & 83.8 & .1398 & NS \\
\hline Range & 1 & 37.9 & 329 & 575.3 & 9999 & NS & 1 & 13.2 & 204 & 242.9 & .8235 & NS \\
\hline Global richness & 1 & .08 & 272 & 449.8 & .3693 & NS & 1 & .15 & 120 & 138.5 & .2407 & NS \\
\hline
\end{tabular}

Note: For each categorical or continuous grouping variable, the results of the analysis are given with degrees of freedom ( $\mathrm{df}) \mathrm{and}$ heterogeneity $(Q)$ between $\left(_{\mathrm{b}}\right)$ and within $\left(_{\mathrm{w}}\right)$ group levels. Significance levels were obtained by 9,999 randomizations $\left(P_{\text {rand }}\right)$ and are adjusted to correct for multiple use of data $\left(P_{\text {adj }}\right)$; NS $=$ not significant.

** $P<.01$.

nificantly (table 2). For marine habitats, regional gradients were stronger in the Atlantic than any other ocean (fig. $4 A$ ), and local gradients were weaker in the Indian Ocean than in the Atlantic (app. C). For terrestrial and freshwater gradients, the New World harbored the strongest gradients at regional scales (fig. 4A). In contrast to longitude, there was no difference in gradient strength between the Northern and Southern Hemispheres (table 2), which showed almost identical effect sizes at both scales (fig. 4B).

Marine and terrestrial studies showed stronger gradients than freshwater studies (fig. 4C), resulting in a significant difference between realms at the regional scale and a similar but nonsignificant trend at the local scale (table 2). A finer typification of habitats explained significant heterogeneity in effect sizes at both spatial scales (table 2). At regional scales, pelagic marine habitats had very strong gradients (fig. $5 \mathrm{~A}$ ), matched only by gradients from the deep sea benthos. Weak regional gradients were confined to freshwaters, lakes as well as streams, whereas there was little variation between terrestrial habitats. The difference between coastal and deep sea benthos was consistent at local scales (app. C), where also significantly weaker gradients in lakes than in streams were observed. In the terrestrial realm, caves and biota (for parasites) revealed weak gradients, with minor variation between the other gradients.

The study grain (mean area used to assess diversity) did not affect $r_{z}$ significantly, neither at regional nor at local scales (table 2). However, the differences between local and regional gradient strength were mirrored by the differences between $r_{z}$ measured at small and large areas (fig. $6 A)$. The latitudinal range of the study did not affect $r_{z}$ (table 2; fig. 6B). The strength was not influenced by the global species richness of the target organism group (table 2; fig. $6 C$ ).

\section{The Slope of the Latitudinal Gradient}

The slope of the gradient showed less significant variation with grouping variables than the strength of the gradient (table 4), due to larger variation (larger heterogeneity) resulting in larger CIs for $b$ compared to $r_{z}$. However, many patterns were similar for both effect sizes.

As for $r_{z}$, significantly steeper (i.e., more negative) $b$ with increasing body mass was observed at both spatial scales (table 4; fig. $2 B$ ). The parameters of the weighted regression between body mass and effect size $b$ were also highly consistent at both spatial scales (table 3 ).

There was no difference in $b$ between ectotherm and homeotherm organisms (table 4; fig. 3D), but a strong difference in the body mass-effect size regression, which was strongly negative for ectotherms, but positive for homeotherms (table 3). The reversal of the regression for homeotherms was observed at both spatial scales.

Neither dispersal types (fig. 3E) nor trophic levels (fig. $3 F$ ) explained significant variation between slopes (table 4). The relation between effect size and trophic level for slopes resembled the decreasing trend observed for gradient strength (cf. fig. $3 C, 3 F$ ) between autotrophs and omnivores, but slopes were considerably flatter for carnivores. Differences in the regression of effect size on body mass were observed with different dispersal types (table 3), but the interaction changed strongly with spatial scale. No clear difference between passively and actively dispersing organisms was observed in $b$ as for $r_{z}$.

Longitude did not explain significant variation between 

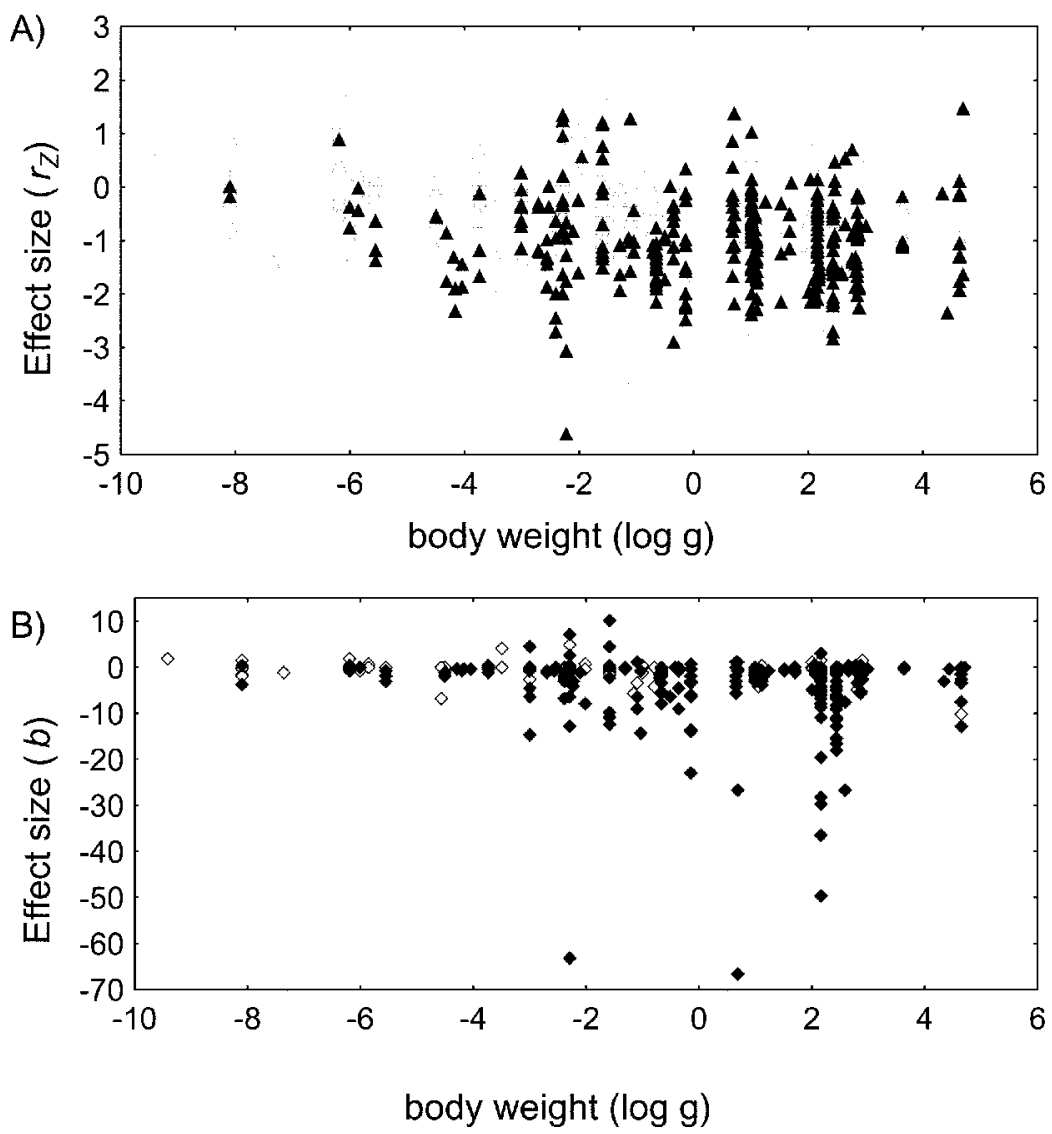

Figure 2: Effect size for $(A)$ strength $\left(r_{z}\right)$ and $(B)$ slope $(b)$ of the latitudinal gradient of diversity in relation to body mass. Open symbols, local gradients; solid symbols, regional gradients.

slopes (table 4), which is due to the high variability in some groups (e.g., Indian Ocean, fig. 4D). It should be noted, though, that the pattern on land resembles very much the pattern found for gradient strength, with largest effect sizes in the New World, and weak effect sizes in Eurafrica and Australasia. For the oceans, however, the pattern is different, with similar effect sizes for the Atlantic and Pacific Oceans and steeper but very variable gradients in the Indian Ocean. As for $r_{z}$, the slope of the gradient did not differ between hemispheres (table 4; fig. 4E).

Different realms did not explain significant variation in $b$ at regional scales (table 4), but the variation between mean effect sizes showed the same trend as observed for $r_{z}$ (fig. 4F). At local scales, terrestrial gradients were significantly steeper than both other gradients (app. C). Different habitat types were significantly different from each other (table 4). For freshwaters and terrestrial gradient, the pattern resembled the differences for gradient strength (fig. 5B). Freshwater mean effect sizes for $b$ were small at regional scales, with a significant difference between stream and lakes at local scales. Terrestrial gradients showed minor variation at regional scales and small effect sizes for caves and biota at local scales (app. C). The difference between $r_{z}$ and $b$ with regard to habitats became obvious in marine environments. Both in the benthos and in the pelagial, effect sizes were larger (more negative) in coastal areas than in the open ocean or deep sea (fig. $5 B$ ).

Increasing the grain of the study consistently decreased $b$, i.e., steepened the slope, at both spatial scales (fig. $6 D$ ). The relation was significant at the local scale and marginally nonsignificant at the regional scale (table 4). Additionally, the grain variable well reflected the general difference in effect size between local and regional studies (fig. $6 D$ ). Also the range of latitudes studied affected the gradient slope significantly (table 4 ; fig. $6 E$ ), but with different signs at the different scales. Regionally, $b$ became steeper with increasing range (slope of weighted regression $=-0.0017)$, but locally $b$ became less steep (0.0061).

In contrast to gradient strength, $b$ was closely related to 
Table 3: Regression results for the relation of effect size $\left(r_{z}\right.$ or $\left.b\right)$ on body mass for different data sets at either regional or local scale

\begin{tabular}{|c|c|c|c|c|c|c|}
\hline \multirow[b]{2}{*}{ Data and scale } & \multicolumn{3}{|c|}{$r_{z}$} & \multicolumn{3}{|c|}{$b$} \\
\hline & Intercept & Slope & $k$ & Intercept & Slope & $k$ \\
\hline \multicolumn{7}{|l|}{ All: } \\
\hline Regional & $-.908(.032)$ & $-.039(.014)$ & 335 & $-1.330(.045)$ & $-.097(.018)$ & 254 \\
\hline Local & $-.474(.043)$ & $-.043(.012)$ & 210 & $-.598(.048)$ & $-.078(.012)$ & 116 \\
\hline \multicolumn{7}{|c|}{ Thermoregulation: } \\
\hline \multicolumn{7}{|c|}{ Ectotherm: } \\
\hline Regional & $-.944(.045)$ & $-.059(.019)$ & 237 & $-1.320(.052)$ & $-.133(.022)$ & 181 \\
\hline Local & $-.532(.050)$ & $-.055(.012)$ & 178 & $-.660(.057)$ & $-.093(.014)$ & 102 \\
\hline \multicolumn{7}{|c|}{ Homeotherm: } \\
\hline Regional & $-1.231(.125)$ & $.146(.055)$ & 95 & $-3.265(.266)$ & $.683(.105)$ & 70 \\
\hline Local & $-.283(.470)$ & $-.079(.217)$ & 31 & $-.964(.650)$ & $.152(.303)$ & 13 \\
\hline \multicolumn{7}{|l|}{ Dispersal type: } \\
\hline \multicolumn{7}{|l|}{ Pelagic larvae: } \\
\hline Regional & $-1.312(.115)$ & $-.205(.056)$ & 56 & $-1.665(.133)$ & $-.275(.072)$ & 52 \\
\hline Local & $-.675(.129)$ & $-.131(.046)$ & 51 & $-.350(.100)$ & $-.073(.027)$ & 29 \\
\hline \multicolumn{7}{|l|}{ Flying: } \\
\hline Regional & $-.846(.050)$ & $-.062(.028)$ & 114 & $-2.063(.119)$ & $-.143(.064)$ & 83 \\
\hline Local & $-.470(.104)$ & $.022(.052)$ & 42 & $-1.100(.238)$ & $-.032(.113)$ & 14 \\
\hline \multicolumn{7}{|l|}{ Mobility: } \\
\hline Regional & $-.900(.097)$ & $-.076(.038)$ & 94 & $-1.297(.180)$ & $.023(.067)$ & 71 \\
\hline Local & $-.421(.109)$ & $-.083(.051)$ & 33 & $-.535(.168)$ & $-.146(.076)$ & 14 \\
\hline \multicolumn{7}{|l|}{ Passive: } \\
\hline Regional & $-2.829(.664)$ & $-.366(.126)$ & 14 & $-.693(.386)$ & $-.067(.092)$ & 11 \\
\hline Local & $-.857(.294)$ & $-.097(.047)$ & 50 & $.083(.297)$ & $.048(.051)$ & 29 \\
\hline \multicolumn{7}{|l|}{ Seeds: } \\
\hline Regional & $-.540(.150)$ & $-.059(.068)$ & 48 & $-.202(.388)$ & $-.820(.175)$ & 28 \\
\hline Local & $-.435(.132)$ & $-.114(.080)$ & 21 & $-.871(.300)$ & $-.224(.151)$ & 9 \\
\hline
\end{tabular}

Note: Table presents intercept and slope $( \pm \mathrm{SE})$ from the weighted regression as well as the number of gradients involved $(k)$.

the global species richness of the target organism group. For groups with higher global species richness, $b$ was steeper (fig. $6 F$ ) at both spatial scales. The relation was significant only at regional scales (table 4).

\section{Discussion}

\section{The Generality of the Latitudinal Gradient}

The present analysis is the first truly general assessment of the latitudinal gradient of diversity. The eukaryotic organisms involved represent a large variety of functional and taxonomic groups (app. A) and comprise a range of 14 orders of magnitude in body mass and of five orders of magnitude in global diversity (table 1). The habitats represent all major biotic realms on the planet and many major habitat types, spread over all continents and oceans. Moreover, the studies assessed local or regional diversity on spatial scales ranging from less than $1 \mathrm{~m}^{2}$ to more than 1 million $\mathrm{km}^{2}$ and covered latitude ranges between $10^{\circ}$ and $90^{\circ}$.
The first major conclusion from this general analysis is therefore that the latitudinal decline of diversity is a ubiquitous phenomenon (supporting hypothesis 1). The overall effect sizes for both $r_{z}$ and $b$ were significantly negative. Similarly, most groupwise effect sizes for strength or slope were negative and significantly different from 0 , especially at regional scales (figs. 3-5).

Even those studies not reporting significant declines of diversity with latitude showed an overall significant negative trend of diversity toward the pole. Obviously, the majority of studies not detecting a diversity decline failed to do so because of the limited statistical power of the study. For the studies classified nonsignificant, the mean number of observations was smaller than in significant studies (mean $N$ : 28 vs. 56 ) and the latitudinal range was narrower (mean range: $37^{\circ}$ vs. $47^{\circ}$ ). It is an advantage of meta-analyses that significant central tendencies can even be observed even when there is limited statistical power within single studies or effects are small (Francoeur 2001).

Nevertheless, there were some studies $(k=25$, or $4.3 \%$ of all studies) showing significant positive relations be- 

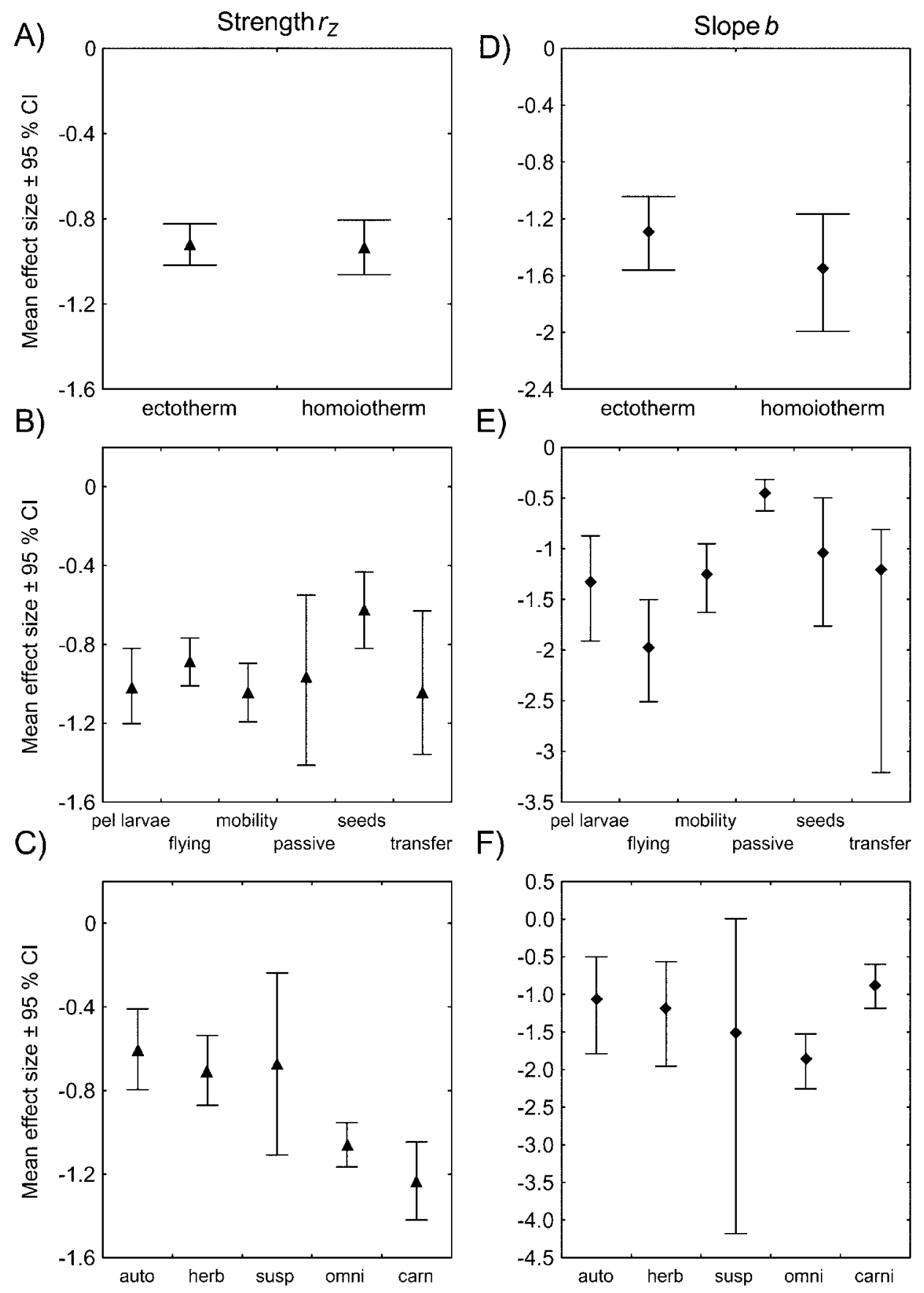

Figure 3: Mean effect size ( $\pm 95 \%$ confidence intervals) for $(A-C)$ strength $\left(r_{z}\right)$ and $(D-F)$ slope $(b)$ of the regional latitudinal gradient of diversity. $A, D$, Effect sizes for ectotherm and homeotherm organisms. $B$, E, Effect sizes for organisms with different dispersal types: pelagic larvae, flying, mobility on ground or in water, passively transported adults, seeds, and parasitic transfer. $C, F$, Effect sizes for organisms with different trophic levels: autotrophs, herbivores, suspension feeders, omnivores, carnivores. 

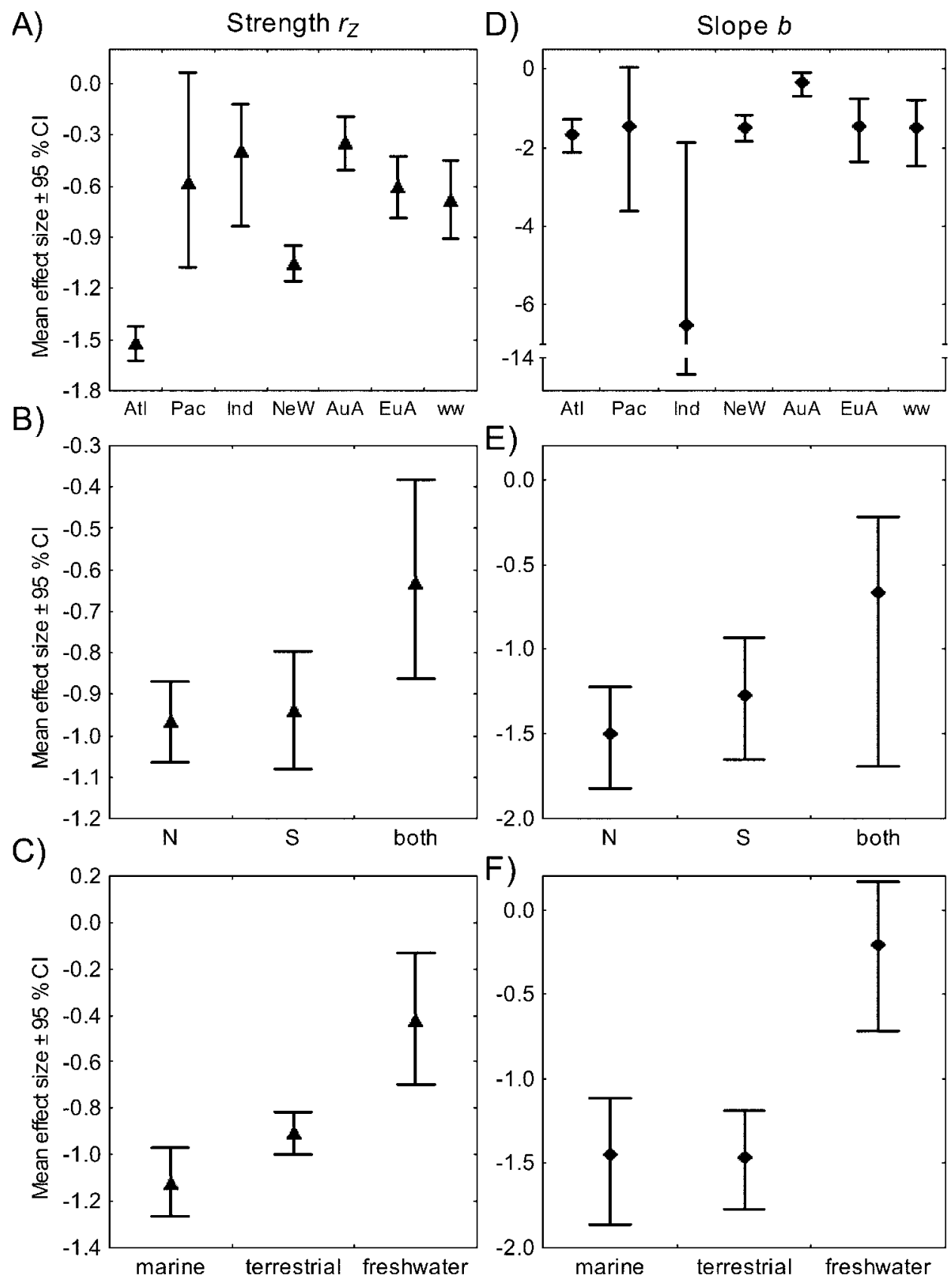

Figure 4: Mean effect size ( $\pm 95 \%$ confidence intervals) for $(A-C)$ strength $\left(r_{z}\right)$ and $(D-F)$ slope $(b)$ of the regional latitudinal gradient of diversity. $A, D$, Effect sizes for different continents or oceans: Atlantic, Pacific, Indian Ocean, New World, Australasia, Eurafrica, worldwide. $B, E$, Effect sizes for different hemispheres: Northern, Southern, both. $C, F$, Effect sizes for different realms.

tween latitude and diversity. These studies mainly represent exceptions in organism groups showing overall strong latitudinal declines such as molluscs (Valdovinos et al. 2003) or birds (Rabenold 1979; see app. A for more de- tails). Aquatic macrophytes as a group tend to show significant diversity increases toward the poles (Crow 1993; Santelices and Marquet 1998). The gradients for ichneumonids, which often were regarded as exceptional (Owen 


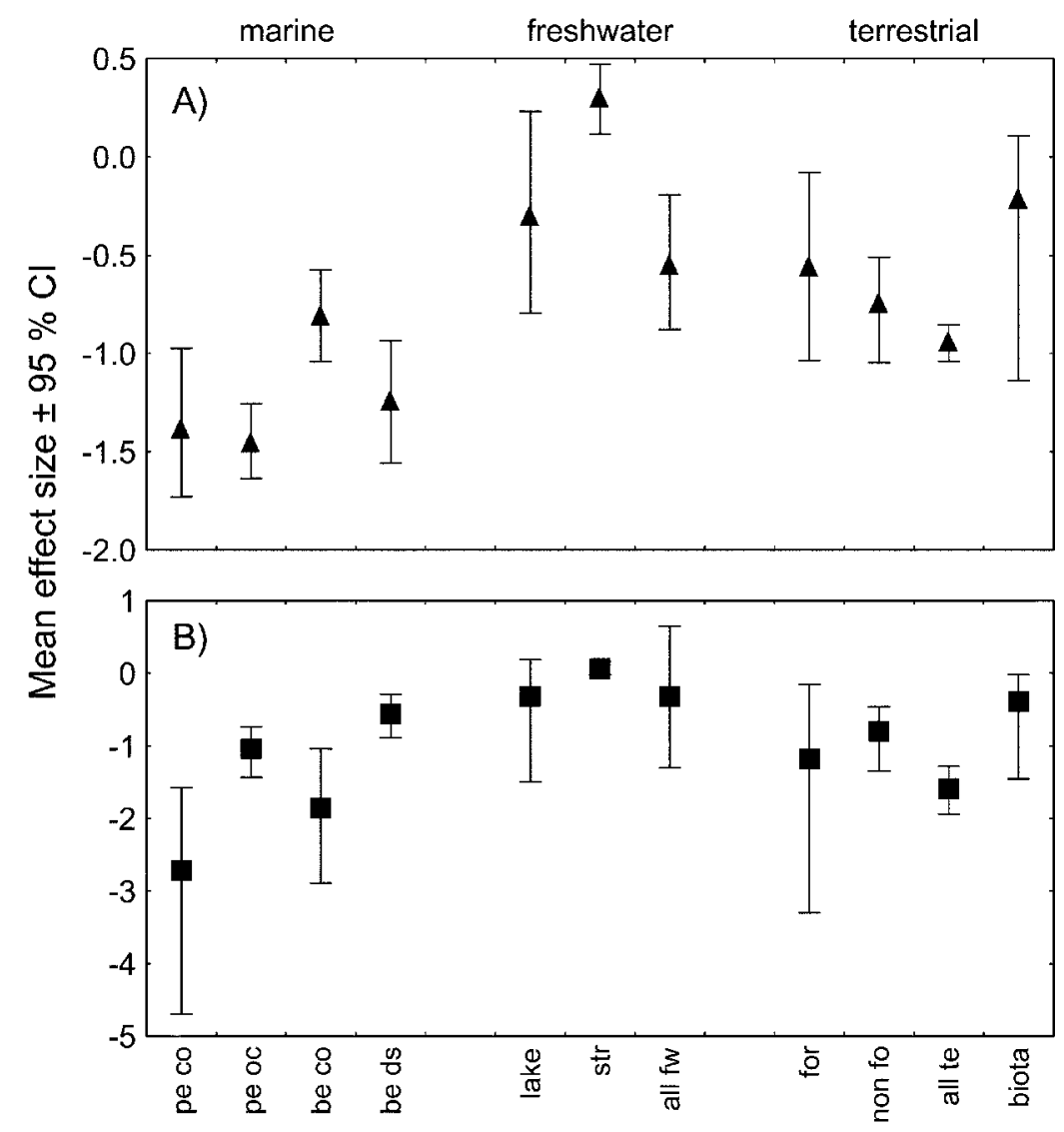

Figure 5: Mean effect size ( $\pm 95 \%$ confidence intervals) for $(A)$ strength $\left(r_{z}\right)$ and $(B)$ slope $(b)$ of the regional latitudinal gradient of diversity. Effect sizes are for the following habitats: pe co, pelagic coast; pe oc, pelagic ocean; be co, benthic coastal; be ds, benthic deep sea; lake, lakes; str, streams; all $f w$, all freshwater; for, forests; non fo, nonforest; all te, all terrestrial; and biota, biota.

and Owen 1974; Janzen 1981), were either positive or negative and did not differ significantly from 0 (mean gradient strength $=-0.1141 ; 95 \% \mathrm{CI}=-1.2407$ to 1.0126). These few positive gradients remain exceptional, though, and the latitudinal gradient of diversity is highly general and arguably the most common statistical pattern of spatial variation in diversity. Despite the generality, however, the gradient is not uniform. The effect sizes show high heterogeneity and significant variation in gradient parameters between scales, geographic regions, realms, habitat types, organism types, and with organism body mass. I will discuss these variations before analyzing the consequences of these patterns for models aiming to explain the latitudinal decline of diversity.

\section{Scale}

Regional gradients of latitudinal diversity decline were consistently stronger and steeper than local gradients (supporting hypothesis 2a; fig. 7). On a highly general level, this analysis corroborated findings for single groups such as bats (Stevens and Willig 2002) or shallow-water gastropods (Spight 1977). At the same time, the mean effect sizes for $b$ and $r_{z}$ were still significantly negative on local scales. The strong scaling effect on both effect sizes has two major implications. First, the decline of diversity toward the pole mainly represents the decline in numbers of regionally coexisting species ( $\gamma$-diversity). Second, the weaker but still significant effect sizes on local scales indicates that local diversity generally relates to the regional diversity but that local interactions may modify diversity at the community level (Stevens and Willig 2002).

These findings have important bearings for the discussion of regional imprints on local species richness (Cornell and Lawton 1992; Lawton 1999; Srivastava 1999; Hillebrand and Blenckner 2002). Statistical relationship between regional and local diversity were used to indicate the relative importance of regional (historical) factors versus local ecological interactions for local diversity (Cornell and Lawton 1992; Lawton 1999; Srivastava 1999). These 

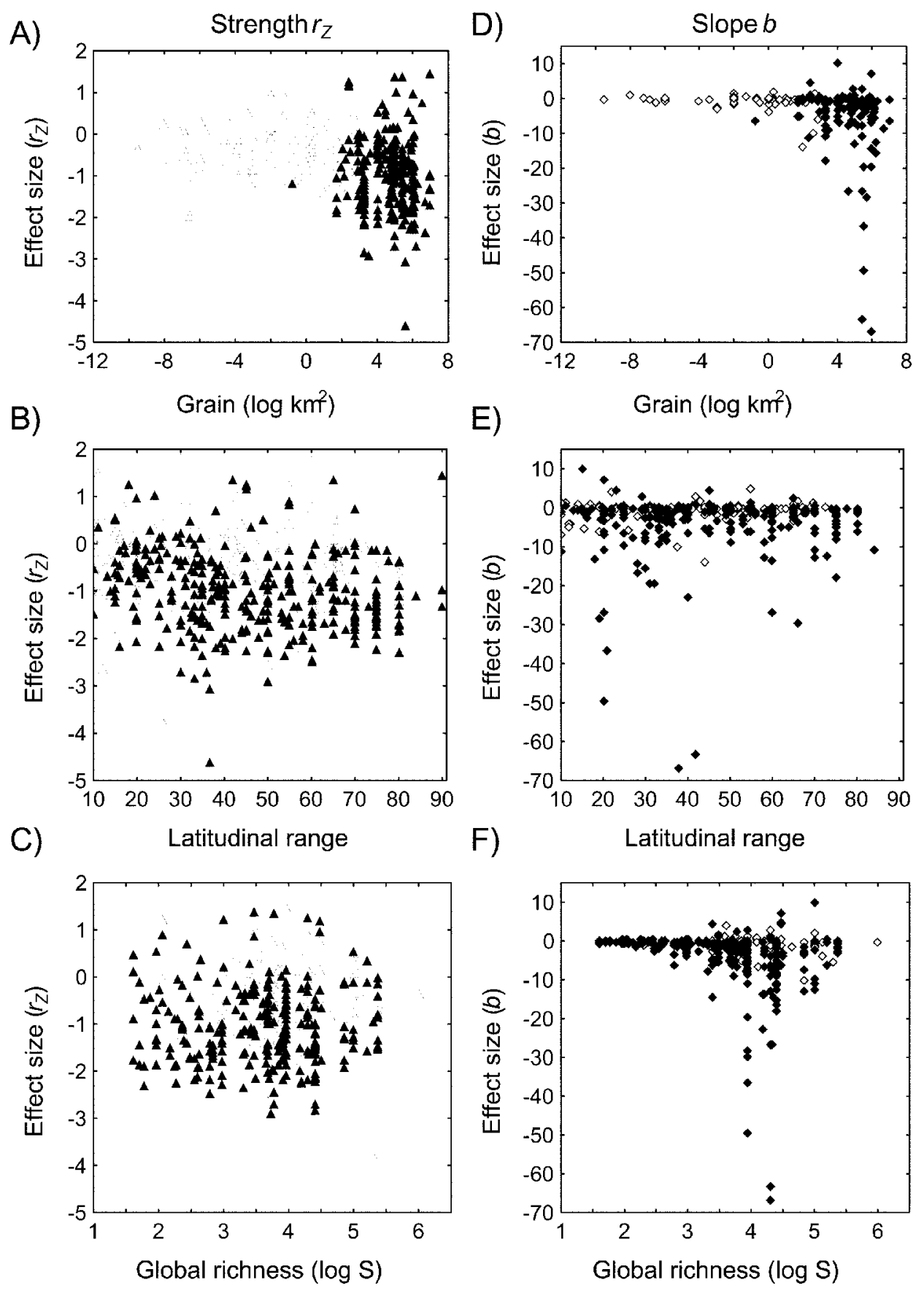

Figure 6: Effect size for $(A-C)$ strength $\left(r_{z}\right)$ and $(D-F)$ slope $(b)$ of the latitudinal gradient of diversity in relation to $(A, D)$ the grain of sampling, $(B, E)$ the range of latitudes studied, and $(C, F)$ the global species richness of the organisms studied. Open symbols, local gradients; solid symbols, regional gradients.

statistical relationships have been criticized for their strong bias toward spatial autocorrelation (Hillebrand and Blenckner 2002). Still, recent studies combining manipulation of ecological interactions with analysis of the re- gional species pool concluded on a simultaneous importance of both factors (Shurin et al. 2000). On the global scale of the present analysis, the patterns found for regional and local diversity support this idea. The significant local 
Table 4: Analysis of heterogeneity for the slope $(b)$ of the latitudinal gradient of diversity at either regional or local scales

\begin{tabular}{|c|c|c|c|c|c|c|c|c|c|c|c|c|}
\hline \multirow[b]{2}{*}{ Variable } & \multicolumn{6}{|c|}{ Regional } & \multicolumn{6}{|c|}{ Local } \\
\hline & $\mathrm{df}_{\mathrm{b}}$ & $Q_{\mathrm{b}}$ & $\mathrm{df}_{\mathrm{w}}$ & $Q_{w}$ & $P_{\text {rand }}$ & $P_{\text {adj }}$ & $\mathrm{df}_{\mathrm{b}}$ & $Q_{\mathrm{b}}$ & $\mathrm{df}_{\mathrm{w}}$ & $Q_{w}$ & $P_{\text {rand }}$ & $P_{\text {adj }}$ \\
\hline Body mass & 1 & 27.5 & 253 & $2,871.6$ & .0001 & $* *$ & 1 & 43.1 & 115 & 507.0 & .0001 & $* *$ \\
\hline Thermoregulation & 1 & 7.6 & 251 & $2,818.1$ & .2986 & NS & 1 & 2.9 & 115 & 570.9 & .3817 & NS \\
\hline Dispersal type & 5 & 81.1 & 247 & $2,621.0$ & .0477 & NS & 5 & 66.3 & 110 & 478.7 & .0173 & NS \\
\hline Trophic level & 6 & 113.9 & 248 & $2,640.8$ & .0210 & NS & 6 & 33.4 & 110 & 448.1 & .1859 & NS \\
\hline Longitude & 6 & 47.4 & 248 & $2,625.4$ & .2989 & NS & 6 & 49.4 & 110 & 424.9 & .0922 & NS \\
\hline Hemisphere & 2 & 17.3 & 251 & $2,923.7$ & .2834 & NS & 2 & 1.4 & 113 & 500.6 & .8429 & NS \\
\hline Realm & 2 & 42.3 & 250 & $2,859.3$ & .0440 & NS & 2 & 49.4 & 114 & 505.5 & .0016 & * \\
\hline Habitat & 10 & 150.2 & 242 & $2,641.1$ & .0425 & NS & 13 & 104.8 & 102 & 422.3 & .0597 & NS \\
\hline Grain & 1 & .9 & 191 & $2,194.3$ & .0052 & + & 1 & 1.5 & 52 & 190.6 & .0001 & $* *$ \\
\hline Range & 1 & .6 & 252 & $2,915.6$ & .0001 & $\star *$ & 1 & 8.1 & 115 & 532.0 & .0001 & $* *$ \\
\hline Global richness & 1 & 252.5 & 253 & $2,756.8$ & .0001 & $* *$ & 1 & 16.7 & 112 & 485.1 & .0086 & NS \\
\hline
\end{tabular}

Note: For each categorical or continuous grouping variable, the results of the analysis are given with degrees of freedom (df) and heterogeneity $(Q)$ between $\left(_{\mathrm{b}}\right)$ and within $\left(_{w}\right)$ group levels. Significance levels were obtained by 9,999 randomizations $\left(P_{\text {rand }}\right)$ and are adjusted to correct for multiple use of data $\left(P_{\text {adj }}\right)$; NS = not significant.

$+P<.1$.

${ }^{*} P<.05$.

** $P<.01$.

gradients reflect the effect of regional diversity on the number of locally coexisting species, whereas the differences in gradient strength and slopes reflect the modification of local richness patterns by ecological interactions. A central future task in macroecology will therefore be to understand systematic variation in the relation between $\alpha$ - and $\gamma$ diversity ( $\beta$-diversity).

A possible systematic difference between local and regional gradients is the use of range maps to assess diversity at regional scales. The actual method to convert range maps into regional diversity differed between studies, but often gaps in range distributions were interpolated, increasing the spatial autocorrelation in the diversity data (W. Jetz, personal communication). The difference between scales could thus be due to the difference in diversity assessment rather than real scale differences. However, this concern is probably negligible: regional diversity was assessed not only by range maps ( $k=182$ gradients) but also by independent estimates of diversity within regions, such as countries or provinces $(k=150)$. Restricting the analysis of scale to the latter regional studies still reveals weaker local $(k=201$, mean effect size $=-0.39,95 \%$ $\mathrm{CI}=-0.4623$ to -0.3068$)$ than regional gradients $(k=150$, mean effect size $=-0.6535,95 \%$ CI $=$ -0.7584 to -0.5484$)$. The difference was significant for $r_{z}\left(P_{\text {adj }}<.01\right)$ and also for the difference between regional and local slopes $\left(P_{\text {adj }}<.01\right)$.

The grain of the studies, measured as log-transformed "sampling" area, varied tremendously and mirrored the difference between regional and local scales. Within these predefined scale groups, however, the strength of the gra- dient was not affected by sampling grain, whereas larger sampling areas resulted in steeper gradient slopes (fig. 7). Previous studies found either invariance of the gradient for bats and marsupials at regional scales ranging from 1,000 to $25,000 \mathrm{~km}^{2}$ (Lyons and Willig 1999) or less obvious gradients at increasing spatial scales for hummingbirds in South America (Rahbek and Graves 2000). Compared to both these studies, the present analysis covers a much broader range of sampling areas, almost 12 orders of magnitude at the local scale and 6 orders of magnitude at the regional scale. It may thus be concluded that the sampling grain has no general effect on the strength of local or regional latitudinal gradients, although it may be important for single organism types at certain scales (Rahbek and Graves 2000).

The range of latitudes covered had no effect $\left(r_{z}\right)$ or weak effects $(b)$ on the structure of the latitudinal gradient (refuting hypothesis $2 \mathrm{~b}$; fig. 7). For $b$, the effects of range width were moreover opposing for local and regional gradients. Studies covering less than $10^{\circ}$ latitude were excluded from my analysis, although latitudinal differences in diversity may be visible at even smaller range size (Gotelli and Ellison 2002). Beyond the limit of $10^{\circ}$, no systematic change in effect sizes occurred, which is astonishing in light of the debate over how the spillover of high tropical richness into adjacent subtropical areas (Blackburn and Gaston 1997; Ruggiero 1999) or the thorough inclusion of high polar diversity (Gray 2001) might affect the latitudinal gradient.

The global species richness of the organism group influenced the slope (fig. 7) but not the strength of the 


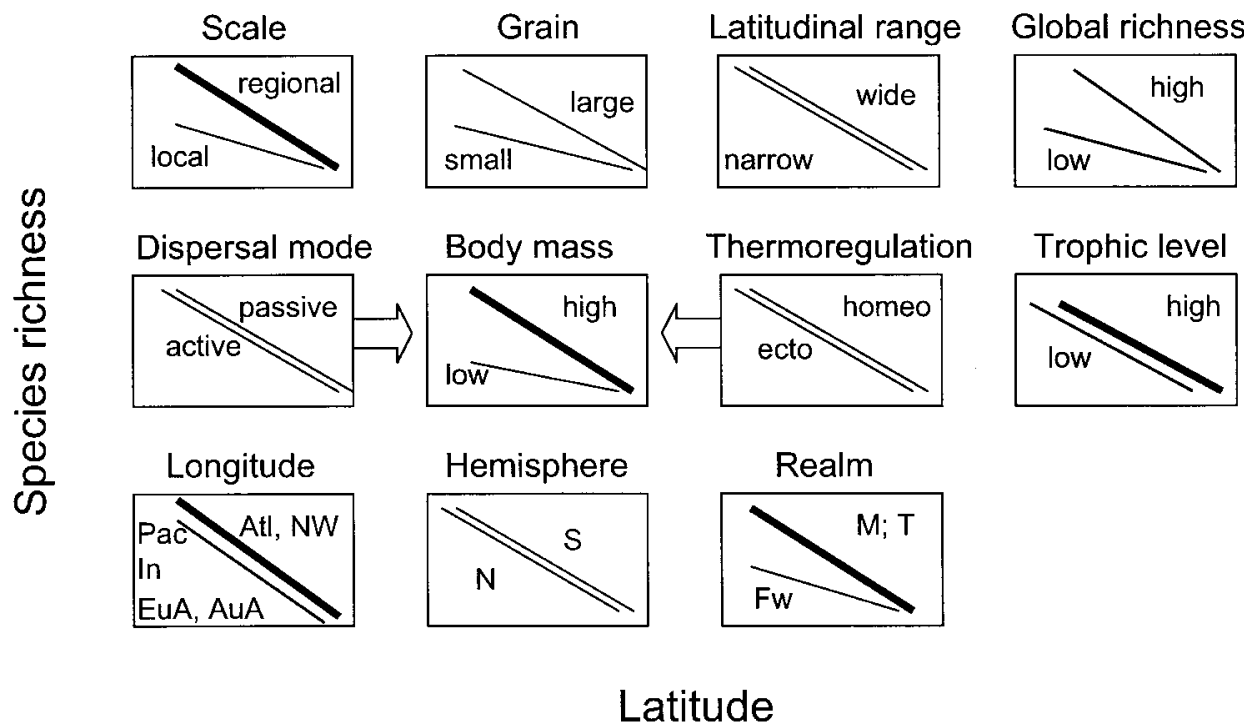

Figure 7: Synoptic summary of variable effects on the strength and slope of the latitudinal gradient. The graphs depict the trend of species richness with latitude (from the equator to the poles) and the effects of 11 variables on the slope (shown as change in slope) and on the strength (shown as change in line thickness). The slope of the latitudinal gradient was affected by the scale of the analysis, the sampling grain, the global richness of the group investigated, the body mass of the organisms, and the realm. Moreover, the slope changed with latitudinal range, but with contrasting signs at different spacial scales. The strength of the gradient differed with scale, trophic level, body mass, longitude, and the realm. Dispersal type and thermoregulation indirectly influenced the body mass-effect size relations (arrows).

latitudinal gradient (partly supporting, partly refuting hypothesis $2 \mathrm{c}$ ). Defining the target organism group more broadly with respect to global species richness must obviously affect the slope of the gradient because the global species richness sets a limit for the steepness of the gradient. More importantly, though, the correlation between latitude and diversity was not significantly different if diversity is analyzed for a small group of species (a family or genus with less than 100 species) or for large classes or phyla representing 10,000 to hundreds of thousands of species.

\section{Organism Features}

Organism body mass had consistent impact on both strength and slope of the gradient (supporting hypothesis $3 a)$. The relation was significant at both spatial scales and revealed almost identical quantitative relations between body mass and effect sizes (fig. 7). The importance of body mass for $r_{z}$ had previously been shown with a much smaller database involving 150 gradients (Hillebrand and Azovsky 2001).

Despite the high generality of the pattern, it is less obvious how it is generated. Before discussing possible mechanisms, it should be noted that systematic errors such as lower taxonomic knowledge of smaller organisms are not able to explain the systematic variation of gradient param- eters with body mass. First, the decrease of gradient strength and slopes is visible along the complete gradient and remains significant when excluding unicellular and small metazoan organisms. This was shown by reanalyzing the body mass regressions for certain dispersal groups such as flying metazoans (including only bats, birds, and insects), seed-dispersing multicellular plants, or metazoans with pelagic larvae. Second, many gradients for small organisms originate from single authors assessing diversity around the world, reducing the risk of systematic underestimation of tropical diversity. Nevertheless, new tools and refined taxonomy may have an impact on gradient structure for least known organisms. It should also be noted that the body mass impact on the gradient is significant only over a wide range of sizes, whereas inverse tendencies can be found within constrained body mass ranges (Cardillo 2002).

It is well known, both from the renowned "Bergmann's rule" found for mammals (Ashton et al. 2000; Freckleton et al. 2003) and in the systematic variation of invertebrate body size distributions with latitude (Gillooly and Dodson 2000; Roy et al. 2001), that body size within organism groups can vary with latitude. By contrast, the present analysis shows that the structure of the latitudinal gradient varies systematically with body mass across organism groups. Body mass clearly has major physiological and ecological implications (Peters 1983) and is under strong 
evolutionary control (Blanckenhorn 2000). Two aspects systematically related to body mass are dispersal rates and population density. Small organisms should have higher dispersal by chance due to their high population sizes, high transportability (Finlay et al. 1996; Hillebrand et al. 2001), and short generation times (Peters 1983; Gillooly et al. 2002). The lower weight and generally higher abundance of small organisms and their fast population growth increase the chance to reach new habitats and establish populations therein. For unicellular eukaryotes, local abundance patterns mirror global abundance patterns (Finlay 2002), and local community composition is less affected by geographic distance than for larger organisms (Hillebrand et al. 2001). These patterns suggest that small organisms may show even distributions of diversity due to rapid dispersal and random sampling of the global diversity pool. Additionally, body mass may influence net diversification due to less geographic separation and, often, vegetative reproduction strategies, limiting the global species pool (Fenchel 1993).

The dispersal hypothesis is partially supported by the variation of the body mass regression with dispersal type. Dispersal type had no direct effect on $b$ and $r_{z}$ (refuting hypothesis $3 \mathrm{~b}$; fig. 7), but for organisms with passive dispersal, the regression between body mass and $r_{z}$ was steeper than for organisms dispersing by own flight or mobility (table 3). Dispersal type and body mass were thus clearly interlinked, strengthening the idea that the body mass impact on the latitudinal gradient is due to dispersal processes. However, the variation was not consistent for both spatial scales and both parameters $b$ and $r_{z}$.

Alternatively, body mass allometrically scales to metabolic rates (Peters 1983; Enquist et al. 1998), development time (Gillooly et al. 2002), and to population density (Allen et al. 2002; Belgrano et al. 2002). Allen et al. (2002) described the relation of mass-corrected population density of ectotherms to temperature and the relation of temperature-corrected population density of ecto- and homeotherms to body mass.

In spite of the strong effect of thermoregulation on the above mentioned relations, the present analysis showed that gradient parameters for ectotherm organisms did not differ from homeotherm organisms on any scale (refuting hypothesis 3d; fig. 7). Still, possible differences in ectotherms and endotherms may have been masked by covarying differences in body mass. Reanalyzing the body mass impact on the gradient parameters for both groups separately revealed that ectotherms alone were responsible for the pattern. Even a reversal of the regression between body mass and $b$ was seen for homeotherms (lower $b$ with increasing body mass). These results indicate an important role of energy-related factors for the latitudinal gradients. Allometric relations of population density to temperature and body mass might indeed have strong consequences for global species richness (Allen et al. 2002), but it remains to be analyzed whether these relations can explain different gradient structure between organisms with different body mass.

An unprecedented result was the strong relation of regional gradient strength to trophic level (supporting hypothesis 3c; fig. 7). The relation is not due to systematic changes in body mass with trophic levels because autotrophs included trees as well as algae, and carnivores included chaetognaths as well as vertebrates. Several alternative explanations are possible: First, the pattern could be directly generated by the ecological interactions between the trophic levels. However, the pattern was confined to regional gradients, whereas the effect of trophic interactions should be visible especially at local scales (Huston 1999). Second, the pattern may derive from a positively reinforced correlation between diversity in adjacent trophic levels, where higher diversity at basal levels founds higher diversity in the next higher trophic levels. If this were true, the "founding" effect has to be disproportionate; that is, an increase in producer diversity must lead to an even larger increase in consumer diversity. It has been shown that diversity in adjacent trophic levels in fact might be positively related (Siemann et al. 1999; Hawkins and Porter 2003) but it has also been questioned whether this correlation is causal (Hawkins and Porter 2003). To my knowledge, a disproportionate effect of basal on top diversity has not been shown so far. Third, the restriction of the pattern to regional gradients points at variation in range-size distributions and thus beta diversity over trophic levels as a possible proximate explanation. The final explanation involves statistical patterns of the food web itself. Two seemingly disparate patterns are known: higher species richness in food webs results in a higher proportion of top-level species and lower proportion of intermediate species (Martinez 1994), and the slope of the species-area curve becomes steeper with increasing trophic level (Holt et al. 1999). Both factors do not necessarily hold on the scale of macroecology, and the general validity of the scaling of top-level predators with food web size is not without debate (Havens 1992; Martinez 1994). Still, these findings indicate two processes possibly reinforcing the latitudinal gradient at higher trophic levels, which would disproportionally increase with the higher overall richness and the higher biome area of the Tropics.

\section{Geographic Position}

The strength and slope of the latitudinal gradient varied significantly with longitude (i.e., between continents or oceans, supporting hypothesis 4 a) but not between hemispheres (refuting hypothesis 4 b; fig. 7). On land, New 
World gradients were stronger (and slightly steeper) than those in Eurafrica or Australasia. Interestingly, the narrow Central American isthmus interrupting the American land masses did not reduce gradient strength in contrast to the predicted importance of area for the latitudinal gradient (Rosenzweig 1995). Australia represents a diversity hotspot for some aquatic organisms such as bivalves (Crame 2000) but reveals often weak latitudinal gradients on land due to adverse climatic conditions at low latitude (Schall and Pianka 1978; Abensperg Traun and Steven 1997). Similarly, Eurafrican longitudes are also characterized by arid areas on the Southern Hemisphere. Additionally, the different geological background of different oceans (Poore and Wilson 1993) or terrestrial regions (Qian and Ricklefs 2000) has been evoked to explain their different regional species richness. However, the present analysis showed weaker and more variable gradients for the Pacific, especially at regional scales, although the Pacific-Indian Oceans are older than the Atlantic. Still, postglacial history may contribute to the continental differences because different orientation of major dispersal barriers in Europe versus America or Asia have largely influenced the effect of and the recovery from glaciation (Blondel and Mourer-Chauviré 1998). In general terms, the Americas may represent uninterrupted biome gradients in that north-south direction, whereas transverse deserts and alpine barriers increase discontinuity in Europe, Africa, and Australia.

Several authors postulated differences in diversity patterns between Southern and Northern Hemispheres because of different biome areas, different land : ocean size ratios, different geological age, and different oceanography (Gaston and Williams 1996; Wilson 1998; Gray 2001). On a general level, no such difference was found in the present analysis (fig. 7). Gradients on the Northern Hemisphere are neither stronger nor steeper than on the Southern Hemisphere. This does not contradict the findings that gradients on the two hemispheres differ within single organism groups, among others described for New World birds (Gaston and Williams 1996) and for foraminiferans (Culver and Buzas 2000). However, it is clearly not warranted to envision latitudinal gradients as a primarily northern phenomenon.

\section{Realms and Habitats}

The strength of the gradient was significantly different between the major realms (partly supporting hypothesis $5 \mathrm{a}$ ), and both strength and slope differed with habitat types (supporting hypothesis $5 b$ ). Latitudinal diversity gradients in freshwater were weaker and flatter than their terrestrial or marine counterparts (fig. 7). Weak gradients in lakes have been proposed quite early (Hubendick 1962), but the difference had not been shown on this highly general level.
Possible explanations are manifold: in contrast to both marine and terrestrial environment, the freshwater realm is geographically isolated in small "freshwater islands"; that is, even by joining local habitats into regions, the region consists of rather isolated habitats. Furthermore, the body mass distribution is skewed toward small organisms in freshwater (this database, mean log g wet weight: -2.4 ) compared to marine $(-1.8)$ or terrestrial (0.9) environments. Additionally, as biome area presumably contributes to the latitudinal gradient (Rosenzweig 1995), freshwaters differ less in tropical versus temperate biome size because the majority of large lakes and many large rivers are in temperate regions (Wetzel 2001). The last argument becomes interesting when comparing streams and lakes at the local scale (app. C). Seemingly, the global distribution of area for large rivers has a larger tropical peak than the distribution for large lakes (Wetzel 2001), and actually on local scales the gradients for running waters were both stronger and steeper than for lakes.

In contrast to freshwater, marine gradients were as strong or slightly stronger compared to terrestrial gradients. This result is remarkable because Clarke (1992) asked only a decade ago if general latitudinal gradients can be found in the sea (a more detailed account of marine gradients will be published separately). The marine gradients also showed substantial variation between habitats, with strong gradients in the pelagic ocean and in the deep sea. The strong pelagic gradients oppose the idea that higher spatial heterogeneity in the Tropics is crucial for the latitudinal diversity gradient. Also within the terrestrial realm, habitats with high architectural complexity (forests) did not show gradients differing from grasslands, wetland, or other less structured habitats. Recent analyses emphasized the importance of heterogeneity (O'Brien et al. 2000; Diniz et al. 2002), with special emphasis on topography or elevational heterogeneity (Rahbek and Graves 2001; Ruggiero 2001).

\section{Conclusion and Outlook}

This article constitutes the first general test for consistent quantitative variation in latitudinal gradients across a large variety of organisms and habitats. The analysis corroborated that the latitudinal gradient of diversity is a highly general spatial pattern of diversity with very few notable exceptions. At the same time, the strength and the slope of the gradient show significant variation with the scale of the analysis and with factors describing features of the organism (body mass, trophic level) and the habitat (geographic position, realm, and habitat type). Latitudinal gradients are mainly a regional phenomenon, which are less strong in freshwaters than in terrestrial or marine environments. The strength and the slope of the gradient in- 
crease with body mass, and the strength increases with trophic level. The relation between effect size (strength or slope) and body mass differs with dispersal mode and between homeotherm and ectotherm organisms.

These results do not serve to directly falsify or support the models proposed to explain the latitudinal diversity gradients, but the presence of strong statistical patterns has important implications for the assumptions and predictions made by the different models.

The observed generality of the latitudinal gradient and the variation with scale do not conform to explanations involving many different local processes, which mainly act at local scales (Huston 1999). Ecological interactions such as competition or consumption (including parasitism) clearly can regulate local diversity (Huston 1999; Shurin et al. 2000; Worm et al. 2002), but the importance for the latitudinal gradient has to be questioned. This analysis thus adds to recent studies failing to find a consistent change in ecological interactions with latitude (Lambers et al. 2002; Ollerton and Cranmer 2002) or concluding that large-scale diversity patterns are not due to variations in community richness (Collins et al. 2002; Stevens and Willig 2002).

Mid-domain models predict the generality of the gradient without involving biological factors (Colwell and Hurtt 1994; Colwell and Lees 2000). The generality of the gradient observed in the present analysis supports the idea of an inevitable poleward decline of diversity. The middomain models were criticized for the structure of the null model (Bokma et al. 2001; Diniz et al. 2002) and for the restricted importance of mid-domain effects for narrowranging species (Jetz and Rahbek 2002), which may account for a large proportion of the tropical diversity. The present analyses additionally pose the question whether the observed differences in gradient strengths and slopes are congruent with null model predictions. Does random placement of geographic ranges only set a general tendency toward higher tropical species richness whereas the strength and slope of the trend are controlled by differences in organisms and habitats? To answer this question, mid-domain models would have to be calculated for different frequency distributions of species ranges and range shapes, which are related to organism and habitat characteristics, and compared to the real data set published here.

The global distribution of area (Terborgh 1973; Rosenzweig 1995), energy (Wright 1983; Currie 1991; Allen et al. 2002), and spatial heterogeneity (topography; O'Brien et al. 2000; Rahbek and Graves 2001; Ruggiero 2001; Diniz et al. 2002) varies tremendously with latitude. These factors have all been proposed to explain (parts of) the latitudinal diversity decline, resulting in an ongoing debate on the causal mechanism (Rohde 1992; Rosenzweig 1995;
Huston 1999; Gaston and Blackburn 2000). The debate has not produced a consensus whether there is a single primary cause (Rohde 1992) or whether these factors act in combination (Gaston and Blackburn 2000). Partly, this failure is due to a lack of consistency in defining these factors, in defining the processes by which these factors operate, and in defining the scales on which they operate. From the present analysis, an interaction of energy- and area-related processes is supported, because many significant factors relate to differences in energy acquisition and processing (body mass, trophic level) or in area (realms and habitats) or both (continents). Additionally, the generality of the pattern strongly suggests that the main acting principles are very basic, giving priority to simple allometric rules such as relations of species richness to temperature (Allen et al. 2002).

The effective evolutionary time hypothesis assumes that tropical areas accumulated most species because speciation increases with the gradients in area, energy, and spatial heterogeneity, reinforced by the longer geological stability of the Tropics (Rohde 1992). Concurrently, it has been observed that long-term climatic oscillations such as Milankovich-cycles reduce persistent cladogenesis at higher latitudes (Jansson and Dynesius 2002). The hypothesis fits well with observations from fossil records showing that the tropical areas are centers of evolutionary novelty (Crane and Lidgard 1989; Jablonski 1993) with higher evolutionary speed than temperate areas (Cardillo 1999) and a higher proportion of species without fossil records (i.e., from recent diversification) and with restricted distribution (Buzas and Culver 1999). Moreover, higher tropical diversity of rhizopods could be related to higher increase in diversity through geological time in the Tropics than in temperate regions (Buzas et al. 2002). The study by Buzas et al. (2002) suggests the importance of a general comparison of the recent gradients analyzed here to information on fossil gradients. The nonequilibrium approach of the effective evolutionary time hypothesis also requires mechanisms preventing the equalization of diversity during evolutionary time. The body mass impact observed in this analysis might indicate the importance of dispersal limitation for the maintenance of the diversity gradient.

\section{Acknowledgments}

This article profited from interactions with many colleagues commenting, discussing, and correcting earlier drafts: A. P. Allen, A. I. Azovsky, A. Belgrano, P. Eklöv, A. Fitter, W. Jetz, H. K. Lotze, B. Malmqvist, U. Sommer, L. Tranvik, and B. Worm. The article was improved by comments from R. K. Colwell and one anonymous reviewer. S. Floeder and U. Sommer helped with the synoptic figure. Financial support is acknowledged from a Marie Curie 
Individual Fellowship, the Institute for Marine Research Kiel, and the Swedish National Research Council.

\section{Literature Cited}

Abensperg Traun, M., and D. Steven. 1997. Latitudinal gradients in the species richness of Australian termites (Isoptera). Australian Journal of Ecology 22:471-476.

Allen, A. P., J. H. Brown, and J. F. Gillooly. 2002. Global biodiversity, biochemical kinetics, and the energeticequivalence rule. Science 297:1545-1548.

Ashton, K. G., M. C. Tracy, and A. de Queiroz. 2000. Is Bergmann's rule valid for mammals? American Naturalist 156:390-415.

Belgrano, A., A. P. Allen, B. J. Enquist, and J. F. Gillooly. 2002. Allometric scaling of maximum population density: a common rule for marine phytoplankton and terrestrial plants. Ecology Letters 5:611-613.

Blackburn, T. M., and K. J. Gaston. 1997. The relationship between geographic area and the latitudinal gradient in species richness in New World birds. Evolutionary Ecology 11:195-204.

Blanckenhorn, W. U. 2000. The evolution of body size: what keeps organisms small? Quarterly Review of Biology 75:385-407.

Blondel, J., and C. Mourer-Chauviré. 1998. Evolution and history of the western Palaearctic avifauna. Trends in Ecology \& Evolution 13:488-492.

Bokma, F., J. Bokma, and M. Mönkkönen. 2001. Random processes and geographic species richness patterns: why so few species in the north? Ecography 24:43-49.

Buzas, M. A., and S. J. Culver. 1999. Understanding regional species diversity through the log series distribution of occurrences. Diversity and Distributions 8: 187-195.

Buzas, M. A., L. S. Collins, and S. J. Culver. 2002. Latitudinal difference in biodiversity caused by higher tropical rate of increase. Proceedings of the National Academy of Sciences of the USA 99:7841-7843.

Cardillo, M. 1999. Latitude and rates of diversification in birds and butterflies. Proceedings of the Royal Society of London B 266:1221-1225.

- 2002. Body size and latitudinal gradients in regional diversity of New World birds. Global Ecology and Biogeography 11:59-65.

Clarke, A. 1992. Is there a latitudinal diversity cline in the sea? Trends in Ecology \& Evolution 7:286-287.

Collins, S. L., S. M. Glenn, and J. M. Briggs. 2002. Effect of local and regional processes on plant species richness in tallgrass prairie. Oikos 99:571-579.

Colwell, R. K., and G. C. Hurtt. 1994. Nonbiological gradients in species richness and a spurious Rapoport effect. American Naturalist 144:570-595.
Colwell, R. K., and D. C. Lees. 2000. The mid-domain effect: geometric constraints on the geography of species richness. Trends in Ecology \& Evolution 15:70-76.

Cornell, H. V., and J. H. Lawton. 1992. Species interactions, local and regional processes, and limits to the richness of ecological communities: a theoretical perspective. Journal of Animal Ecology 61:1-12.

Crame, J. A. 2000. Evolution of taxonomic diversity gradients in the marine realm: evidence from the composition of recent bivalve faunas. Paleobiology 26:188214.

Crane, P. R., and S. Lidgard. 1989. Angiosperm diversification and paleolatitudinal gradients in Cretaceous floristic diversity. Science 246:675-678.

Crow, G. E. 1993. Species diversity in aquatic angiosperms: latitudinal patterns. Aquatic Botany 44:229-258.

Culver, S. J., and M. A. Buzas. 2000. Global latitudinal species diversity gradient in deep-sea benthic foraminifera. Deep-Sea Research Part I Oceanographic Research Papers 47:259-275.

Currie, D. J. 1991. Energy and large-scale patterns of animal- and plant-species richness. American Naturalist 137:27-49.

Currie, D. J., A. P. Francis, and J. T. Kerr. 1999. Some general propositions about the study of spatial patterns of species richness. Ecoscience 6:392-399.

Darwin, C. 1859. The origin of species by means of natural selection. J. Murray, London.

Diniz, J. A. F., C. E. R. de Sant'Ana, M. C. de Souza, and T. F. L. V. B. Rangel. 2002. Null models and spatial patterns of species richness in South American birds of prey. Ecology Letters 5:47-55.

Enquist, B. J., J. H. Brown, and G. B. West. 1998. Allometric scaling of plant energetics and population density. Nature 395:163-165.

Fenchel, T. 1993. There are more small than large species? Oikos 68:375-378.

Finlay, B. J. 2002. Global dispersal of free-living microbial eukaryote species. Science 296:1061-1063.

Finlay, B. J., G. F. Esteban, and T. Fenchel. 1996. Global diversity and body size. Nature 383:132-133.

Francoeur, S. N. 2001. Meta-analysis of lotic nutrient amendment experiments: detecting and quantifying subtle responses. Journal of the North American Benthological Society 20:358-368.

Freckleton, R. P., P. H. Harvey, and M. Pagel. 2003. Bergmann's rule and body size in mammals. American Naturalist 161:821-825.

Gaston, K. J., and T. M. Blackburn. 2000. Pattern and process in macroecology. Blackwell Scientific, Oxford.

Gaston, K. J., and P. H. Williams. 1996. Spatial patterns in taxonomic diversity. Pages 202-229 in K. Gaston, ed. 
Biodiversity: a biology of numbers and difference. Blackwell Scientific, Cambridge, Mass.

Gillooly, J. F., and S. I. Dodson. 2000. Latitudinal patterns in the size distribution and seasonal dynamics of New World, freshwater cladocerans. Limnology and Oceanography 45:22-30.

Gillooly, J. F., E. L. Charnov, G. B. West, V. M. Savage, and J. H. Brown. 2002. Effects of size and temperature on developmental time. Nature 417:70-73.

Gotelli, N. J., and A. M. Ellison. 2002. Biogeography at a regional scale: determinants of ant species density in New England bogs and forests. Ecology 83:1604-1609.

Gray, J. S. 2001. Antarctic marine benthic biodiversity in a world-wide latitudinal context. Polar Biology 24:633641.

Gurevitch, J., and L. V. Hedges. 1993. Meta-analysis: combining the results of independent experiments. Pages 378-398 in S. M. Scheiner and J. Gurevitch, eds. Design and analysis of ecological experiments. Chapman \& Hall, New York.

Havens, K. 1992. Scale and structure in natural food webs. Science 257:1107-1109.

Hawkins, B. A., and E. E. Porter. 2003. Does herbivore diversity depend on plant diversity? the case of California butterflies. American Naturalist 161:40-49.

Hillebrand, H., and A. I. Azovsky. 2001. Body size determines the strength of the latitudinal diversity gradient. Ecography 24:251-256.

Hillebrand, H., and T. Blenckner. 2002. Regional and local impact on species diversity: from pattern to processes. Oecologia (Berlin) 132:479-491.

Hillebrand, H., F. Watermann, R. Karez, and U. G. Berninger. 2001. Differences in species richness patterns between unicellular and multicellular organisms. Oecologia (Berlin) 126:114-124.

Holt, R. D., J. H. Lawton, G. A. Polis, and N. D. Martinez. 1999. Trophic rank and the species-area relationship. Ecology 80:1495-1505.

Hubendick, B. 1962. Aspects on the diversity of freshwater fauna. Oikos 13:249-261.

Huston, M. A. 1999. Local processes and regional patterns: appropriate scales for understanding variation in the diversity of plants and animals. Oikos 86:393-401.

Jablonski, D. 1993. The tropics as a source of evolutionary novelty through geological time. Nature 364:142-144.

Jansson, R., and M. Dynesius. 2002. The fate of clades in a world of recurrent climatic change: Milankovitch oscillations and evolution. Annual Review of Ecology and Systematics 33:741-777.

Janzen, D. H. 1981. The peak in North American ichneumonid species richness lies between $38 \mathrm{~N}$ and $42 \mathrm{~N}$. Ecology 63:532-537.

Jetz, W., and C. Rahbek. 2001. Geometric constraints ex- plain much of the species richness pattern in African birds. Proceedings of the National Academy of Sciences of the USA 98:5661-5666.

- 2002. Geographic range size and determinants of avian species richness. Science 297:1548-1551.

Koleff, P., and K. J. Gaston. 2001. Latitudinal gradients in diversity: real patterns and random models. Ecography 24:341-351.

Lambers, J. H. R., J. S. Clark, and B. Beckage. 2002. Density-dependent mortality and the latitudinal gradient in species diversity. Nature 417:732-735.

Lawton, J. H. 1999. Are there general laws in ecology? Oikos 84:177-192.

Lees, D. C., C. Kremen, and L. Andriamampianina. 1999. A null model for species richness gradients: bounded range overlap of butterflies and other rainforest endemics in Madagascar. Biological Journal of the Linnean Society 67:529-584.

Levin, S. A. 2001. Encyclopedia of biodiversity. Academic Press, San Diego, Calif.

Loreau, M. 2000. Are communities saturated? on the relationship between $\alpha, \beta$ and $\gamma$ diversity. Ecology Letters 3:73-76.

Losos, J. B., and D. Schluter. 2000. Analysis of an evolutionary species-area relationship. Nature 408:847-850.

Lyons, S. K., and M. R. Willig. 1997. Latitudinal patterns of range size: methodological concerns and empirical evaluations for New World bats and marsupials. Oikos 79:568-580.

- 1999. A hemispheric assessment of scale dependence in latitudinal gradients of species richness. Ecology 80:2483-2491.

Martinez, N. D. 1994. Scale-dependent constraints on food-web structure. American Naturalist 144:935-953.

O'Brien, E. M., R. Field, and R. J. Whittaker. 2000. Climatic gradients in woody plant (tree and shrub) diversity: water-energy dynamics, residual variation and topography. Oikos 89:588-600.

Ollerton, J., and L. Cranmer. 2002. Latitudinal trends in plant-pollinator interactions: are tropical plants more specialised? Oikos 98:340-350.

Osenberg, C. W., O. Sarnelle, S. D. Cooper, and R. D. Holt. 1999. Resolving ecological questions through meta-analysis: goals, metrics and models. Ecology 80: 1105-1117.

Owen, D. F., and J. Owen. 1974. Species diversity in temperate and tropical Ichneumonidae. Nature 249:583584.

Peters, R. H. 1983. The ecological implications of body size. Cambridge University Press, Cambridge.

Pianka, E. R. 1966. Latitudinal gradients in species diversity: a review of concepts. American Naturalist 100:3346. 
Poore, G. C. B., and G. D. F. Wilson. 1993. Marine species richness. Nature 361:597-598.

Qian, H., and R. E. Ricklefs. 2000. Large-scale processes and the Asian bias in species diversity of temperate plants. Nature 407:180-182.

Rabenold, K. N. 1979. A reversed latitudinal diversity gradient in avian communities of eastern deciduous forests. American Naturalist 114:275-286.

Rahbek, C., and G. R. Graves. 2000. Detection of macroecological patterns in South American hummingbirds is affected by spatial scale. Proceedings of the Royal Society of London B 267:2259-2265.

- 2001. Multiscale assessment of patterns of avian species richness. Proceedings of the National Academy of Sciences of the USA 98:4534-4539.

Rohde, K. 1992. Latitudinal gradients in species diversity: the search for the primary cause. Oikos 65:514-527.

. 1997. The larger area of the tropics does not explain latitudinal gradients in species diversity. Oikos 79: 169-172.

Rosenberg, M. S., D. C. Adams, and J. Gurevitch. 2000. MetaWin: statistical software for meta-analysis. Version 2.0. Sinauer, Sunderland, Mass.

Rosenzweig, M. L. 1995. Species diversity in space and time. Cambridge University Press, Cambridge.

Rosenzweig, M. L., and E. A. Sandlin. 1997. Species diversity and latitudes: listening to area's signal. Oikos 80: 172-176.

Roy, K., D. Jablonski, and J. W. Valentine. 2001. Climate change, species range limits and body size in marine bivalves. Ecology Letters 4:366-370.

Ruggiero, A. 1999. Spatial patterns in the diversity of mammal species: a test of the geographic area hypothesis in South America. Ecoscience 6:338-354.

- 2001. Size and shape of the geographical ranges of Andean passerine birds: spatial patterns in environmental resistance and anisotropy. Journal of Biogeography 28:1281-1294.

Santelices, B., and P. A. Marquet. 1998. Seaweeds, latitudinal diversity patterns, and Rapoport's rule. Diversity and Distribution 4:71-75.

Schall, J. J., and E. R. Pianka. 1978. Geographical trends in numbers of species. Science 201:679-686.
Shurin, J. B., J. E. Havel, M. A. Leibold, and B. Pinel Alloul. 2000. Local and regional zooplankton species richness: a scale-independent test for saturation. Ecology 81: 3062-3073.

Siemann, E., J. Haarstad, and D. Tilman. 1999. Dynamics of plant and arthopod diversity during old field succession. Ecography 22:406-414.

Sokal, R. R., and F. J. Rohlf. 1995. Biometry. W. H. Freeman, New York.

Spight, T. M. 1977. Diversity of shallow-water gastropod communities on temperate and tropical beaches. American Naturalist 111:1077-1097.

Srivastava, D. S. 1999. Using local-regional richness plots to test for species saturation: pitfalls and potentials. Journal of Animal Ecology 68:1-16.

Stevens, R. D., and M. R. Willig. 2002. Geographical ecology at the community level: perspectives on the diversity of new world bats. Ecology 83:545-560.

Terborgh, J. 1973. On the notion of favorableness in plant ecology. American Naturalist 107:481-501.

Valdovinos, C., S. A. Navarrete, and P. A. Marquet. 2003. Mollusk species diversity in the Southeastern Pacific: why are there more species towards the pole? Ecography 26:139-144.

von Humboldt, A. (1828) 1993. Alexander von Humboldt über das Universum: die Kosmosvorträge 1827/28 in der Berliner Singakademie. Insel, Frankfurt.

Wetzel, R. G. 2001. Limnology. Academic Press, San Diego, Calif.

Wetzel, R. G., and G. E. Likens. 1991. Limnological analyses. Springer, New York.

Wilson, G. D. F. 1998. Historical influences on deep-sea isopod diversity in the Atlantic Ocean. Deep-Sea Research Part II Topical Studies in Oceanography 45:279_ 301.

Worm, B., H. K. Lotze, H. Hillebrand, and U. Sommer. 2002. Consumer versus resource control of species diversity and ecosystem functioning. Nature 417:848-851.

Wright, D. H. 1983. Species-energy theory: an extension of species-area theory. Oikos 41:496-506.

Associate Editor: Chris D. Thomas 
Copyright of American Naturalist is the property of University of Chicago Press and its content may not be copied or emailed to multiple sites or posted to a listserv without the copyright holder's express written permission. However, users may print, download, or email articles for individual use. 